\title{
RESPOSTA DE SORGO INOCULADO COM Azospirillum brasilense A DOSES DE NITROGÊNIO EM COBERTURA
}

\author{
Roberto Kennedy Mortate ${ }^{1}$, Bruno de Moraes Nunes ${ }^{2}$, Estevam Matheus Costa ${ }^{3}$, Eleusa Maria Ferreira \\ Rocha $^{2}$, Matheus Vinicius Abadia Ventura ${ }^{4}$, Leandro Spíndola Pereira ${ }^{3}$
}

\author{
${ }^{1}$ Engenheiro Agrônomo, Universidade do Estado de Minas Gerais - Unidade de Ituiutaba (UEMG), R. Ver. Geraldo Moisés da Silva, s/n \\ - Universitário, Ituiutaba/MG - CEP: 38.302-192 \\ 2Professor, Universidade do Estado de Minas Gerais - Unidade de Ituiutaba (UEMG), R. Ver. Geraldo Moisés da Silva, s/n - \\ Universitário, Ituiutaba/MG - CEP: 38.302-192 \\ ${ }^{3}$ Enegnheiro Agrônomo, Instituto Goiano de Agricultura (IGA), Fazenda Rancho Velho, Montividiu/GO - CEP: 75.915-000 \\ ${ }^{4}$ Doutorando em Ciência Agrárias, Instituto federal goiano - campus rio verde (IF Goiano), Rodovia Sul Goiana, Km 01, Zona Rural, Rio \\ Verde/GO - CEP: 75.901-970 \\ *Autor para correspondência: Roberto Kennedy Mortate, robertomortate@gmail.com
}

\begin{abstract}
RESUMO: Estirpes de Azospirillum brasilense conseguem fornecer parte do nitrogênio que as gramíneas necessitam. Objetivou-se avaliar o efeito combinado da inoculação de A. brasilense e nitrogênio sobre as características agronômicas do sorgo granífero e a população de bactérias diazotrópicas nas raízes. 0 trabalho foi composto por duas etapas: 1- Ensaio a campo: T1= $200 \mathrm{Kg}_{\text {. ha- }}{ }^{-1}$ de ureia $(\mathrm{U}), \mathrm{T} 2=300 \mathrm{~mL} \mathrm{ha}^{-1}$ de inoculante + $50 \mathrm{Kg} \mathrm{ha}^{-1}$ de U, T3=300 mL ha-1 $+100 \mathrm{Kg} \mathrm{ha}^{-1} \mathrm{de} \mathrm{U,} \mathrm{T4=300} \mathrm{mL} \mathrm{ha-1}+150 \mathrm{Kg} \mathrm{ha}^{-1}$ de U e T5=300 mL ha-1 200 $\mathrm{Kg}_{\text {ha }}{ }^{-1} \mathrm{de} \mathrm{U}$, avaliando caracteres morfológicos e componentes de produção; 2- Ensaio em casa de vegetação: $\mathrm{T} 1=300 \mathrm{~mL} \mathrm{ha}^{-1} \mathrm{de} \mathrm{MG}, \mathrm{T} 2=300 \mathrm{~mL} \mathrm{ha}^{-1}$ de inoculante $+50 \mathrm{Kg} \mathrm{ha}^{-1} \mathrm{de} \mathrm{U}, \mathrm{T} 3=300 \mathrm{~mL} \mathrm{ha}^{-1}+100 \mathrm{Kg} \mathrm{ha}^{-1} \mathrm{de} \mathrm{U}, \mathrm{T} 4=$ $300 \mathrm{~mL} \mathrm{ha}^{-1}+150 \mathrm{Kg} \mathrm{ha}^{-1}$ de U e T5 $=300 \mathrm{~mL} \mathrm{ha}^{-1}+200 \mathrm{Kg} \mathrm{ha}^{-1}$ de U, avaliando clorofila total, comprimento radicular e população de bactérias. Nos caracteres morfológicos, fisiológicos e componentes de produção, os tratamentos que receberam 150 e $200 \mathrm{Kg}$ de ureia ha-1 combinado com inoculação foram superiores aos demais, no entanto, em casa de vegetação o tratamento com $200 \mathrm{~kg}$ de ureia ha-1 inibiu a proliferação das bactérias diazotróficas. Houve incrementos na produtividade do sorgo granífero quando utilizada inoculação, sendo possível a redução da adubação nitrogenada em $25 \%$ com a utilização de inoculação.
\end{abstract}

PALAVRAS CHAVE: Adubação nitrogenada, bactérias diazotróficas, simbiose, Sorghum bicolor

\section{RESPONSE OF SORGHUM INOCULATED WITH Azospirillum brasilense AT NITROGEN RATES IN COVERAGE}

ABSTRACT: Strains of Azospirillum brasilense, which they gramineas need. The objective of this study was to evaluate the combined effect of A. brasilense and nitrogen inoculation on the agronomic characteristics of sorghum and the root population of diazotropic bacteria. The weight was added by two steps: 1 - Field test: $T 1=200 \mathrm{~kg}$.ha-1 urea (U), T2 $=300 \mathrm{~mL} \mathrm{ha}^{-1}$ inoculant $+50 \mathrm{~kg} \mathrm{ha}^{-1} \mathrm{U}, \mathrm{T} 3=300 \mathrm{~mL} \mathrm{ha}^{-1}+100 \mathrm{Kg} \mathrm{ha}^{-1}$ of $\mathrm{U}, \mathrm{T} 4=300 \mathrm{~mL} \mathrm{ha}^{-1}+150$ $\mathrm{Kg} \mathrm{ha}^{-1}$ of $\mathrm{U}$ and $\mathrm{T} 5=300 \mathrm{~mL} \mathrm{ha}^{-1}+200 \mathrm{Kg} \mathrm{ha}^{-1}$ of $\mathrm{U}$, evaluating morphological characters and components of production; 2 - Greenhouse test: T1 $=300 \mathrm{~mL} \mathrm{ha}^{-1}$ of inoculant, $\mathrm{T} 2=300 \mathrm{~mL} \mathrm{ha}^{-1}$ of MG $+50 \mathrm{~kg} \mathrm{ha}^{-1}$ of U, T3 $=300$ $\mathrm{mL} \mathrm{ha}^{-1}+100 \mathrm{~kg} \mathrm{ha}^{-1}$ of $\mathrm{U}, \mathrm{T} 4=300 \mathrm{~mL} \mathrm{ha}^{-1}+150 \mathrm{Kg} \mathrm{ha}^{-1}$ of $\mathrm{U}$ and $\mathrm{T} 5=300 \mathrm{~mL} \mathrm{ha}^{-1}+200 \mathrm{Kg} \mathrm{ha}^{-1}$ of U, evaluated in total chlorophyll, root length and population of bacteria. Morphological enumerations, physiological and production components, treatments that received 150 and $200 \mathrm{~kg}$ of urea ha-1. inhibited the proliferation of diazotrophic bacteria. Incremental innovation in grain yield after inoculation, being possible the reduction of nitrogen fertilization in $25 \%$ with the use of inoculation.

KEY WORDS: Nitrogen fertilization; diazotrophic bacteria; Sorghum bicolor, symbiosis 


\section{INTRODUÇÃO}

O sorgo, Sorghum bicolor, é o quinto cereal mais cultivados em todo o mundo, ficando atrás do arroz, trigo, milho e cevada (Tardin et al., 2009). A área total é de 816,6 mil hectares, com uma produtividade média de $2.789 \mathrm{~kg} / \mathrm{ha}$ (CONAB, 2019). Dentre as espécies de sorgo cultivadas no Brasil, o sorgo granífero é o que apresenta maior importância econômica. 0 sorgo granífero adapta-se muito bem a inúmeros ambientes, inclusive onde existem condições de déficit hídrico (Nakao et al., 2014).

O nitrogênio é um nutriente que influencia na produção de grãos, sendo o nutriente exigido em maiores quantidades pelo sorgo. De acordo com Sousa e Lobato (2004), para se produzir 4 toneladas de grãos de sorgo por hectare, deve ser realizado a adubação com 20 e $30 \mathrm{Kg}$ de nitrogênio ( $\mathrm{N}$ ) por hectare, na semeadura e em cobertura, respectivamente. O sorgo tem uma demanda de $70 \%$ do nitrogênio até os sessenta dias após a emergência, momento em que a planta se encontra na metade do seu ciclo e com cerca da metade de sua biomassa (Vanderlip, 1999).

As bactérias promotoras de crescimento de plantas (BPCP) correspondem a um grupo de microrganismos benéficos às plantas que apresentam à capacidade de colonizar a superfície das raízes, rizosfera, e tecidos internos das plantas (Döbereiner et al., 1995). As BPCP estimulam o crescimento vegetal por meio da capacidade de fixação biológica de nitrogênio; aumento na atividade da redutase do nitrato quando crescem endofiticamente nas plantas; solubização de fosfato, produção de hormônios como auxinas, citocininas, giberilinas, etileno e uma variedade de outras moléculas e também atuam no controle de patógenos (Hungria, 2011). Diversas pesquisas destacam a importância da substituição parcial ou total da utilização de insumos, principalmente da adubação nitrogenada, visando a redução dos custos de produção. Dentre as tecnologias, estudos apontam a utilização de bactérias diazotróficas fixadoras de nitrogênio (Lemos, 2011). Trabalhos utilizando a inoculação associada à adubação nitrogenada, estão sendo desenvolvidos para a cultura do milho e trigo e sorgo apresentando resposta favorável. Dessa forma, surge a necessidade da recomendação da dose do incoculante e da adubação nitrogenada ideal a cultura sorgo, surgindo a necessidade de desenvolvimento de pesquisas nesse sentido (Rampim et al., 2012; Dartora et al., 2013).

O gênero Azospirillum abrange um grupo de BPCP de vida livre que é encontrado em quase todos os lugares da terra. Há relatos de que as bactérias desse gênero podem ser endofíticas facultativas (Döbereiner e Pedrosa, 1987; Hungria, 2011). Estudos sobre aplicação de bactérias diazotróficas na cultura do sorgo com a perspectiva de reduzir o uso de fertilizantes nitrogenados é de suma importância uma vez que este nutriente é essencial para a cultura, apresenta baixa eficiência de aproveitamento e contribui para o aumento dos gases do efeito estufa (Vanderlip, 1999).

Com esta pesquisa objetivou-se avaliar o efeito combinado da inoculação de Azospirillum brasilense e nitrogênio sobre as características agronômicas do sorgo granífero e a população de bactérias diazotróficas nas raízes.

\section{MATERIAL E MÉTODOS}

Foram conduzidos dois experimentos em condições de: 1) campo e 2) casa de vegetação, nas dependências da Universidade do Estado de Minas Gerais - UEMG, unidade Ituiutaba ( $18^{\circ} 58^{\prime} 17.2^{\prime \prime} \mathrm{S}$ e $49^{\circ}$ 26 ' $54.3^{\prime \prime}$ W). 0 experimento de campo foi conduzido de março a julho de 2016. A temperatura e a pluviosidade média de Ituiutaba, no ano de 2016 foi de $23.9^{\circ} \mathrm{C}$, e $1352 \mathrm{~mm}$, respectivamente.

0 inoculante utilizado foi 0 Masterfix Gramíneas $₫$ e a cultivar de sorgo granífero, o híbrido BRS 307. O solo foi classificado como LATOSSOLO VERMELHO (Santos et al., 2013), e antes da instalação dos experimentos apresentava na camada $0-20 \mathrm{~cm}$ as características químicas mostradas na Tabela 1.

Tabela 1. Caracterização química do solo na camada de 0-20 cm antes da instalação do experimento, Ituiutaba, MG

\begin{tabular}{|c|c|c|c|c|c|c|c|c|c|c|c|c|}
\hline $\mathrm{pH}$ & $P$ & $\mathrm{~K}$ & Al & $\mathrm{H}+\mathrm{Al}$ & $\mathrm{Ca}$ & $\mathrm{Mg}$ & SB & $t$ & $\mathrm{~T}$ & M.O & $\mathrm{m}$ & V \\
\hline \multicolumn{4}{|c|}{$. . \mathrm{mg} / \mathrm{dm}^{3} .}$. & \multicolumn{6}{|c|}{ 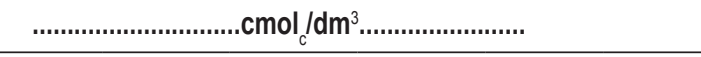 } & g/kg & \multicolumn{2}{|c|}{$\ldots . . . \% \ldots$} \\
\hline 5,6 & 2,9 & 52,5 & 0,13 & 3,75 & 1,15 & 0,72 & 2,0 & 2,1 & 5,75 & 21 & 6 & 34,8 \\
\hline
\end{tabular}


O delineamento foi em blocos casualizados para o experimento de campo e inteiramente casualizados para 0 experimento em casa de vegetação, com cinco tratamentos e quatro repetições. No experimento de campo, as parcelas foram constituídas por3 linhas de 3 metros, com espaçamento de 0,5 metros entre linhas, totalizando $4,5 \mathrm{~m}^{2}$. Considerou-se como área útil a linha central, excluindo $0,5 \mathrm{~m}$ da bordadura de cada linha. 30 dias antes da semeadura foi feita a calagem a lanço, aplicando-se 1,3 tha-1 de calcário (PRNT de 90\%). A adubação de fundação foi constituída da aplicação de $250 \mathrm{~kg} \mathrm{ha}^{-1}$ da formulação 4-14-8.
Os tratamentos foram formados pela inoculação com $300 \mathrm{~mL}$ + doses de adubo nitrogenado tanto para o campo como para a casa de vegetação. Dessa forma, os tratamentos foram constituídos pela inoculação, combinada com a aplicação em cobertura de 50 (T2), 100 (T3), 150 (T4) e 200 (T5) Kg de N ha-1 (Tabelas 2 e $3)$, além de dois tratamentos controle, sendo: somente aplicação em cobertura de $200 \mathrm{Kg} \mathrm{ha}^{-1}$, para o ensaio em campo (Tabela 2), e ausência de aplicação e inoculação, para o ensaio realizado em casa de vegetação (Tabela 3), A adubação nitrogenada em cobertura, foi realizada quando as plantas de sorgo se situavam em estádio fenológico $\mathrm{V}_{6}$, utilizando com fonte mineral a ureia.

Tabela 2. Descrição dos tratamentos no experimento a campo

\begin{tabular}{cc}
\hline Tratamentos & Doses de ureia em cobertura $\left(\mathrm{kg} \mathrm{ha}^{-1}\right)$ \\
\hline T1 (controle) & 200 \\
T2 $\left(300 \mathrm{~mL} \mathrm{ha}^{-1}\right.$ de Masterfix Gramíneas) & 50 \\
T3 $\left(300 \mathrm{~mL} \mathrm{ha}^{-1}\right.$ de Masterfix Gramíneas) & 100 \\
T4 $\left(300 \mathrm{~mL} \mathrm{ha}^{-1}\right.$ de Masterfix Gramíneas) & 150 \\
T5(300 $\mathrm{mL} \mathrm{ha}^{-1}$ de Masterfix Gramíneas) & 200 \\
\hline
\end{tabular}

Tabela 3. Descrição dos tratamentos no experimento em casa de vegetação

\begin{tabular}{cc}
\hline Tratamentos & Doses de ureia $\left(\mathrm{kg} \mathrm{ha}^{-1}\right)$ \\
\hline $\mathrm{T} 1$ (controle) & 50 \\
$\mathrm{~T} 2\left(300 \mathrm{~mL} \mathrm{ha}^{-1}\right.$ de Masterfix Gramíneas $)$ & 100 \\
T3 $\left(300 \mathrm{~mL} \mathrm{ha}^{-1}\right.$ de Masterfix Gramíneas $)$ & 150 \\
$\mathrm{~T} 4\left(300 \mathrm{~mL} \mathrm{ha}^{-1}\right.$ de Masterfix Gramíneas $)$ & 200 \\
T5 $\left(300 \mathrm{~mL} \mathrm{ha}^{-1}\right.$ de Masterfix Gramíneas $)$ & \\
\hline
\end{tabular}

Realizou-se a inoculação com 0 inoculante (Masterfix Gramíneas $\left.^{\circledR}\right)$, na dose de $300 \mathrm{~mL} \mathrm{ha}^{-1}(2 \times 10$ 8 unidades formadoras de colônias $\mathrm{mL}^{-1}$ de Azospirillum brasilense), adicionando-se o produto às sementes em um saco de polipropileno, sendo o conjunto agitado por 3 minutos. Realizou-se a semeadura logo após a inoculação, com o auxílio de semeadora manual, regulada para a distribuição de 160.000 sementes ha-1.

Em uma amostra de 5 plantas por parcelas, aos 120 DAE, aferiu-se o diâmetro do colo (DC), a 0,10 m de altura do solo, com auxílio de paquímetro digital, e a altura de plantas (AP), com auxílio de régua graduada, mediu-se a distância compreendida entre a superfície do solo até a inserção da panícula.

Por ocasião da colheita, realizada aos 120 DAE, foram realizadas avaliações dos componentes de produção, peso de cem grãos, número de grãos por panícula e produtividade, em cinco plantas por parcela.
O estande final de plantas através da contagem do número de plantas em 3 metros lineares, e a produtividade foi determinada por meio da pesagem dos grãos produzidos na área útil de cada parcela, corrigindo a umidade para $13 \%$.

A segunda etapa dos experimentos, realizada em casa de vegetação, conduziu-se o experimento em delineamento inteiramente casualizado (DIC) com cinco tratamentos e quatro repetições. Cada parcela foi composta por um vaso de volume de $5 \mathrm{dm}^{3}$ contendo uma planta de sorgo. 0 substrato utilizado foi composto pela terra coletada no local, cujos atributos químicos se encontram na Tabela 1, onde foi implantado 0 experimento de campo mais a adubação recomendada para a cultura do sorgo (Alves, 1999).

As sementes foram inoculadas com Masterfix Gramíneas ${ }^{\circledR}$ na dose de $300 \mathrm{~mL}^{-1}$ para um estande de 160.000 plantas por hectare. A semeadura foi 
realizada na quantidade de 3 sementes por vaso. Após a emergência das plantas, realizou-se 0 desbaste mantendo 1 planta por vaso. A adubação de cobertura com ureia foi realizada de acordo com a dose de cada tratamento (Tabela 4) no estádio V6, aos 30 DAE. Os vasos foram irrigados diariamente a fim de manter a umidade do solo com $80 \%$ da capacidade de campo.

Tabela 4. Altura de Plantas (AP), Diâmetro de Colmo (DC) e Peso de 100 Grãos (PCG) de plantas da cultura do sorgo, cultivado em campo, submetidas à diferentes doses de ureia com ou sem inoculação

\begin{tabular}{ccccc}
\hline Tratamento & $\begin{array}{c}\text { Dose do inoculante }(\mathbf{m L})+ \\
\text { Uréia em cobertura }\left(\mathbf{k g ~ h a}^{-1}\right)\end{array}$ & $\begin{array}{c}\text { AP } \\
(\mathbf{c m})\end{array}$ & $\begin{array}{c}\text { DC } \\
(\mathbf{m m})\end{array}$ & $\begin{array}{l}\text { PCG } \\
(\mathbf{g})\end{array}$ \\
\hline 1 & $0+200$ & $67,60 \mathrm{~b}^{1}$ & $12,04 \mathrm{a}$ & $3,38 \mathrm{a}$ \\
2 & $300+50$ & $49,61 \mathrm{c}$ & $8,94 \mathrm{c}$ & $3,36 \mathrm{a}$ \\
3 & $300+100$ & $68,61 \mathrm{~b}$ & $10,94 \mathrm{~b}$ & $3,35 \mathrm{a}$ \\
4 & $300+150$ & $76,84 \mathrm{a}$ & $12,31 \mathrm{a}$ & $3,36 \mathrm{a}$ \\
5 & $300+200$ & $77,90 \mathrm{a}$ & $12,37 \mathrm{a}$ & $3,48 \mathrm{a}$ \\
\hline CV $(\%)$ & & 1,99 & 3,73 & 3,38 \\
\hline
\end{tabular}

${ }^{1}$ Médias seguidas por letras distintas nas colunas diferem-se entre si pelo teste de Tukey $(p<0,05)$.

Aos 60 DAE realizou-se a leitura do teor de clorofila total nas folhas com o medidor de clorofila portátil Clorofilog falker®. Em cada planta, realizaramse duas leituras nas folhas mais velhas, e os resultados foram expressos em ICF (Índice de Clorofila Falker).

Realizou-se a retirada, aos 60 dias após a emergência das plantas, dos vasos, realizando lavagem do sistema radicular, e após, com auxílio de régua graduada, mediu-se o comprimento médio das raízes das plantas.

Para estimar a população das bactérias diazotróficas na rizosfera das plantas, utilizou-se a técnica de diluição seriada com o meio de cultivo semisólido NFB (Döbereiner et al., 1999). Para o isolamento e contagem das células, as raízes foram lavadas e desinfetadas superficialmente com álcool $70 \%$ por um minuto, seguido de hipoclorito de sódio $2 \%$ por 5 minutos e lavagem com água destilada autoclavada. Para preparar a solução concentrada, um grama das raízes foi adicionado a $9 \mathrm{~mL}$ de solução salina e maceradas com auxílio de cadinho e pistilo. A solução resultante foi reservada em um tubo Falcon e sob capela de fluxo laminar, diluída sucessivamente até 106. Logo após, inoculou-se $0,1 \mathrm{~mL}$ das diluições $10-4$ a 10-6 em tubos de ensaio contendo $5,0 \mathrm{~mL}$ do meio de cultivo semi-sólido e, em seguida, os tubos foram fechados com algodão e papel alumínio (Döbereiner et al., 1995). Utilizou-se triplicatas para cada diluição inoculada e os tubos foram incubados a $30^{\circ} \mathrm{C}$ em BOD.

No décimo dia de incubação, realizou-se a avaliação, sendo considerados positivos os tubos que apresentaram a formação da película que caracteriza 0 crescimento de bactérias diazotróficas. Esses frascos positivos foram utilizados para estimar o número de células por grama de matéria fresca das raízes, utilizando o método do Número Mais Provável (NMP) (Dobereiner et al., 1995).

Os dados foram submetidos à análise de variância pelo teste $\mathrm{F}$ e demonstrada significância, as médias comparadas pelo teste de Tukey ao nível de $5 \%$ de probabilidade, utilizando o software estatístico Assistat@ (Silva e Azevedo, 2009).

\section{RESULTADOS E DISCUSSÃO}

A altura de planta foi maior nos tratamentos com inoculante combinado com 150 e $200 \mathrm{~kg} \mathrm{ha}^{-1}$ de ureia (Tabela 4). As doses de nitrogênio apresentam efeitos benéficos, principalmente quando associados a inoculação, com o percentual médio de $8 \%$ de superioridade em relação ao controle, como já mencionado por Rocha e Costa (2018), trabalhando com Urochloa brizantha cv Paiaguás inoculada com A. brasilense, associada ou não a diferentes doses nitrogênio. Resultados similares, foram obtidos por Kappes et al. (2011), que observou a influência da inoculação com $A$. brasilense ao trabalhar com milho, encontrando aumento na altura das plantas de milho em decorrência do uso dessa bactéria diazotrófica inoculada na semente.

O diâmetro do colmo foi superior nos tratamentos que receberam as maiores doses de nitrogênio (150 e $200 \mathrm{Kg} \mathrm{ha}^{-1}$ ) via aplicação de ureia em cobertura, independente da inoculação (Tabela 4), dessa forma 0 aumento do diâmetro de colmo não foi favorecido 
pela inoculação de bactérias fixadoras de nitrogênio nos tratamentos com 150 e $200 \mathrm{~kg} \mathrm{ha}^{-1}$, sendo esses resultados também encontrados por Verona et al. (2010) ao inocular Azospirillum sp. na cultura do milho.

0 aumento do diâmetro do colmo das plantas de sorgo é uma vantagem para a cultura, podendo proporcionar maior resistência ao acamamento e favorecer a obtenção de maiores produtividades, uma vez que colmos mais desenvolvidos armazenam maiores quantidades de nutrientes e substâncias orgânicas e inorgânicas que proporcionarão maior produção de grãos (Nakao et al., 2014).

O peso de cem grãos não apresentou diferença entre os tratamentos avaliados (Tabela 4). Em Campus de Dourados-MS, Ohland et al. (2005), trabalhando com efeito de culturas de coberturas antecessora e adubação nitrogenado, nos componentes de produção da cobertura do milho, observou que o peso de grãos é um dos componentes influenciados principalmente pela expressão do genótipo, disponibilidade de nutrientes e das condições climáticas estabelecidas durante os estádios de enchimento dos grãos, no entanto Júnior et al. (2018), trabalhando com doses de fertilizante organomineral mineral, em sorgo granífero, cultivado na segunda safra, não observou efeito dos tratamentos no peso de mil grão, mostrando que para o sorgo essa variável é pouco influenciada, sendo resultados similares ao dessa pesquisa. Portugal et al. (2012) também não verificaram diferenças no peso de cem grãos de milho primeira safra com aplicação foliar de A. brasilense em relação ao sem aplicação foliar.

Para o número de grãos por panícula, os tratamentos contendo 150 e $200 \mathrm{~kg} \mathrm{ha}^{-1}$ de ureia, associados a inoculação com $A$. brasilense, foram os que apresentaram melhores resultados, com acréscimo de aproximadamente $100 \%$ no número de grãos por panícula, para ambos tratamentos, em comparação com a testemunha (T1) (Tabela 5). 0 número de grãos por panícula é um importante componente da produção do sorgo, pois o mesmo reflete diretamente sobre a produtividade da cultura, sendo que em trabalho realizado por Nakao et al. (2014), a aplicação de $A$. brasilense proporcionou maiores rendimentos no número de grãos por panícula de sorgo, contribuindo para maiores incrementos na produtividade.

Tabela 5. Número de Grãos por Panícula, Estande Final e Produtividade da cultura do sorgo, cultivado em campo, submetidas à diferentes doses de ureia com ou sem inoculação

\begin{tabular}{|c|c|c|c|c|}
\hline Tratamento & $\begin{array}{l}\text { Dose do inoculante }(\mathrm{mL})+ \\
\text { Uréia em cobertura }\left(\mathrm{kg} \mathrm{ha}^{-1}\right)\end{array}$ & $\mathrm{N}^{\circ}$ grãos por panícula & $\begin{array}{l}\text { Estande final } \\
\text { (plantas } \mathrm{m}^{-1} \text { ) }\end{array}$ & $\begin{array}{l}\text { Produtividade } \\
\left(\mathrm{kg} \mathrm{ha}^{-1}\right)\end{array}$ \\
\hline 1 & $0+200$ & $174,31 \mathrm{~b}$ & $4,70 b^{1}$ & 553,82 bc \\
\hline 2 & $300+50$ & $100,78 \mathrm{c}$ & $5,50 a$ & $372,48 \mathrm{c}$ \\
\hline 3 & $300+100$ & $199,87 b$ & $5,70 a$ & $763,32 b$ \\
\hline 4 & $300+150$ & $326,18 \mathrm{a}$ & $5,90 \mathrm{a}$ & $1.293,26 \mathrm{a}$ \\
\hline 5 & $300+200$ & 344,62 a & $5,80 a$ & $1.391,18$ a \\
\hline \multicolumn{2}{|r|}{ CV (\%) } & 11,31 & 7,30 & 21,90 \\
\hline
\end{tabular}

${ }^{1}$ Médias seguidas por letras distintas nas colunas diferem-se entre si pelo teste de Tukey $(p<0,05)$.

O estande final de plantas foi afetado pelos tratamentos, sendo observados maiores estandes nos tratamentos que receberam a inoculação $\operatorname{com} A$. brasilense, diferindo do tratamento que não recebeu a inoculação (Tabela 5). Tal fenômeno pode ser atribuído ao fato de que as bactérias presentes na planta, melhoraram a capacidade de absorção de água e nutrientes devido ao maior desenvolvimento dos sistemas radiculares que podem ter sido incrementados pela produção de hormônios vegetais que estas produzem (Quadros et al., 2015). Os efeitos benéficos da inoculação com essas bactérias são significativamente observados quando as plantas passam por determinadas condições de estresse, causadas pela limitação dos recursos de produção como água, luz, nutrientes, $\mathrm{CO}_{2}$ (Hungria et al., 2011).

Quanto à produtividade, os tratamentos contendo a combinação entre inoculação com $A$. brasilense e 150 ou $200 \mathrm{~kg}$ de ureia ha ${ }^{-1}$ foram os que apresentaram maiores produtividades (Tabela 5). Com a utilização destas doses de adubação combinadas com a inoculação, foram obtidos incrementos de 739,41 e 837,36 Kg ha-1, em relação ao tratamento testemunha (T1), e de 529,94 e $837,36 \mathrm{Kg} \mathrm{ha}^{-1} \mathrm{em}$ relação ao tratamento inoculado com adubação de $100 \mathrm{~kg}$ de ureia ha-1 ${ }^{-1}$, para os tratamentos T4 e T5, respectivamente (Tabela 5). 
Entre os dois tratamentos que apresentaram maiores produtividades, é importante salientar que estes não diferiram entre si (T4 e T5), desta forma, a adubação com $150 \mathrm{Kg}$ de ureia ha-1 combinada com inoculação seria a mais viável para o cultivo de sorgo, uma vez que, houve economia de $50 \mathrm{Kg}$ de fertilizante por hectare. Segundo Hungria (2011), esse incremento na produtividade pode ter sido influenciado não só com 0 aumento de $\mathrm{N}$ mas também com outros nutrientes que podem ser disponibilizados pelas bactérias inoculadas.

Kappes et al. (2013), trabalhando com milho também constataram maiores produtividades pela inoculação de sementes com $A$. brasilense. Sala et al. (2007), em estudos com a cultura do trigo, também relataram aumento de produtividade com 0 uso de $A$. brasilense, corroborando com o presente trabalho, que também se assemelham aos dados relatados por GarcíaOlivares et al. (2006) ao trabalharem com a aplicação de $A$. brasilense em sorgo granífero na região norte do México.

A clorofila total foi maior nos tratamentos que receberam aplicação de ureia nas doses de 150 e $200 \mathrm{Kg} \mathrm{ha}^{-1}$, enquanto que o tratamento que não recebeu nem ureia e nem inoculação foi o com menor teor de clorofila em comparação com todos os outros tratamentos (Tabela 6). A elevação no teor de clorofila pode ser explicada pelo fato de que mais de $50 \%$ do nitrogênio total das folhas integram os compostos do cloroplasto e da clorofila (Chapman e Barreto, 1997).

Okon e Vanderleyden (1997) comentaram que o ganho com a Azospirillum spp. vai muito além da fixação do nitrogênio atmosférico, pois com 0 aumento das raízes, as plantas conseguem aumentar a quantidade de nitrogênio absorvido do solo. Um sintoma bastante conhecido da deficiência de $\mathrm{N}$ nas plantas é a diminuição da cor verde, amarelecimento e clorose das folhas mais velhas (baixeiras), devido à alta mobilidade do nitrogênio nas plantas. Sendo assim, plantas mais verdes, são plantas mais nutridas e consequentemente mais produtivas (Taiz et al., 2017).

De acordo com a Tabela 6 , todos os tratamentos que receberam inoculação obtiveram melhor comprimento radicular, quando comparado com 0 tratamento T1 (testemunha), com especial atenção aos tratamentos T4 e T5 que obtiveram as melhores médias diferenciando-se dos demais e não apresentando diferenças entre si. As bactérias do gênero Azospirillum podem estimular o crescimento das plantas por diversas maneiras, sendo as mais relevantes a capacidade de fixação biológica de nitrogênio, produção de hormônios como auxinas, citocininas, giberelinas, etileno e uma variedade de outras moléculas (Hungria, 2011).

Esses hormônios promovem 0 crescimento das raízes, melhorando a capacidade da planta para absorver água, nutrientes e consequentemente 0 crescimento de toda a planta. As mesmas observações são relatadas por Junior et al. (2012) reforçando que este processo disponibiliza nitrogênio assimilável às plantas, e ainda contribuem para a produção de hormônios vegetais, como auxinas e giberelinas, que atuam no crescimento dos vegetais.

Pode-se observar ainda na Tabela 6 que a população de bactérias diazotróficas na rizosfera das plantas de sorgo provenientes de sementes inoculadas com A. brasilense, decresceu à medida que se aumenta a dose de ureia aplicada em cobertura. Os tratamentos T1, T2, T3 e T4 se diferenciaram do tratamento T5 que recebeu a maior dose de ureia (Tabela 6). Embora não tenha sido observada diferença estatística no número de bactérias diazotróficas entre $\mathrm{T} 1, \mathrm{~T} 2, \mathrm{~T} 3 \mathrm{e}$ T4, observou que o tratamento sem aplicação de $A$. brasiliense (T1), resultou em menor teor de clorofila, e comprimento radicular do que os demais tratamentos, o que pode estar relacionado com a ineficiência das espécies de bactérias nativas presente no solo.

Tabela 6. Clorofila Total, Comprimento Radicular e População de Bactérias no cultivo de sorgo, cultivados em vasos em casa de vegetação, submetidas à diferentes doses de ureia com ou sem inoculação,

\begin{tabular}{ccccc}
\hline Tratamento & $\begin{array}{c}\text { Dose do inoculante }(\mathrm{mL})+ \\
\text { Uréia em cobertura }\left(\mathbf{k g ~ h a} \mathbf{-}^{-1}\right)\end{array}$ & $\begin{array}{c}\text { Índice de Clorofila Falker } \\
(\mathrm{ICF})\end{array}$ & $\begin{array}{c}\text { Comprimento Radicular } \\
(\mathbf{c m})\end{array}$ & $\begin{array}{c}\text { População de bactérias } \\
\left(\mathbf{1 0}^{7} \text { células. } \mathbf{g}^{-1}\right)\end{array}$ \\
\hline 1 & $0+0$ & $39,95 \mathrm{~d}^{1}$ & $26,00 \mathrm{c}$ & $3,166 \mathrm{a}$ \\
2 & $300+50$ & $46,12 \mathrm{c}$ & $30,50 \mathrm{bc}$ & $2,633 \mathrm{a}$ \\
3 & $300+100$ & $49,82 \mathrm{~b}$ & $32,00 \mathrm{~b}$ & $2,333 \mathrm{a}$ \\
4 & $300+150$ & $54,07 \mathrm{a}$ & $38,25 \mathrm{a}$ & $2,333 \mathrm{a}$ \\
5 & $300+200$ & $56,12 \mathrm{a}$ & $38,75 \mathrm{a}$ & $0,600 \mathrm{~b}$ \\
\hline
\end{tabular}

${ }^{1}$ Médias seguidas por letras distintas nas colunas diferem-se entre si pelo teste de Tukey $(p<0,05)$. 
Figueiredo (2002), ao analisar o comportamento de estirpes de rizóbio, relatou que as flutuações osmóticas associadas aos períodos de déficit hídrico resultaram na diminuição da sobrevivência das populações de rizóbio no solo ou redução no seu crescimento. Kavadia et al. (2008) destacam que altas concentrações de amônia $\left(\mathrm{NH}_{3}\right)$, e baixas concentrações de oxigênio e carbono, inibem o complexo nitrogenase do Azospirillum, reduzindo a sua população dessas bactérias, similarmente ao que ocorreu nessa pesquisa. As observações quanto ao comportamento fisiológico destes organismos unicelulares também são relatadas por Figueiredo (2002) e Kavadia et al. (2008).

Desta forma, conclui-se que a combinação da inoculação com $A$. brasilense com adubação nitrogenada na dose de 150 e $200 \mathrm{~kg} \mathrm{ha}^{-1}$ de ureia resultou em maior produtividade, além de incrementar 0 teor de clorofila, a altura das plantas o desenvolvimento das raízes de sorgo granífero.

A produtividade de sorgo granífero apresentou incrementos quando as sementes receberam inoculação com Masterfix Gramíneas® e até mesmo redução no uso de adubos nitrogenados em até $25 \%$, quando comparado a áreas que não receberam inoculação.

$\mathrm{E}$ a adubação com $200 \mathrm{Kg} \mathrm{ha}^{-1}$ de ureia nos tratamentos que receberam inoculação com $A$. brasilense inibiu a proliferação das bactérias diazotróficas.

\section{REFERÊNCIAS BIBLIOGRÁFICAS}

Alves, V. M. C.; Vasconcellos, C.A.; Freire, F. M.; Pitta, G. V. E.; França, G. E. Sorgo. In: Ribeiro, A. C.; Guimarães, P. T. G. \& Alvarez, V., V.H. (ed.). Recomendação para 0 uso de corretivos e fertilizantes em Minas Gerais: $5^{\text {a }}$ aproximação. Viçosa: CFSEMG, 1999. 359p.

Chapman, S. C.; Barreto, H. J. Using a chlorophyll meter to estimate specific leaf nitrogen of tropical maize during vegetative growth. Agronomy Joumal, 1997, 89, 1, 557-562.

CONAB, CNDA. Acompanhamento da safra brasileira: grãos. V. 6 - Safra 2018/19 - N. 7 - Sétimo levantamento, Abril 2019, 2019. Disponível em: <https://www.conab. gov.br/info-agro/safras/graos/boletim-da-safra-degraos>, Acesso em: 7 mai 2019.

Dartora, J.; Guimarães, V. F.; Marini, D.; Sander, G. Adubação nitrogenada associada à inoculação com
Azospirillum brasilense e Herbaspirillum seropedicae na cultura do milho. Revista Brasileira de Engenharia Agrícola e Ambiental-Agriambi, 2013, 17, 10, 1023-1029.

Döbereiner, J.; Andrade, V. de O.; Baldani, V. L. D. Protocolos para preparo de meios de cultura da Embrapa Agrobiologia. Embrapa AgrobiologiaDocumentos (INFOTECA-E), 1999, 1-38.

Döbereiner, J.; Baldani, V. L. D.; Baldani, J. I. Como isolar e identificar bactérias diazotróficas de plantas não-leguminosas. Embrapa SPI, 1995, 1-60.

Döbereiner, J.; Pedrosa, F. O. Nitrogen-fixing bacteria in nonleguminous crop plants. Science Tech Publishers, Springer Verlag, Madison, USA, 1987, 1-155.

Tardin, F. D.; Rodrigues, J. A. S.; Coelho, R. R. Cultivo do sorgo. Cultivares. Embrapa Milho e Sorgo. Sistema de Produção, 2010, 2, 1-3.

Figueiredo, M. do V. B., Fatores bióticos e abióticos à fixação biológica de N2, 2002, 43-68.

García-olivares, J. G.; Moreno-medina, V. R.; Rodríguez-luna, I. C.; Mondoza-Herrera, A.; MayekPéreza, N. Biofertilización com Azospirillum brasilense em sorgo, em el norte de México. Agricultura Técnica em México, 2006, 32, 2, 135-141.

Hungria, M. Inoculação com Azospirillum brasilense: Inovação em rendimento a baixo custo, Londrina: Embrapa Soja, 2011, 1-36.

Júnior, J. J. A.; Smiljanic, K. B. A.; Sousa, J. A. P.; Furquim, M. C.; Martins Filho, M. B.; Barros, R. C. Avaliação do sorgo granifero MR 43 na segunda safra "safrinha" região do Sudoeste Goiano com utilização de fertilizante organomineral. In: Anais Colóquio Estadual de Pesquisa Multidisciplinar (ISSN-2527-2500) \& Congresso Nacional de Pesquisa Multidisciplinar. 2018.

Junior, P.; Guimarães, V. F.; Sobreira, L. F. O.; da Silva, B.; Dranski, J. A. L.; Bandeira, K. B.; Oliveira, F. Resposta a Inoculação de Estirpes de Azospirillum brasilense na Cultura do Milho na Região Oeste do Paraná. In: Apresentado ao XXIX CONGRESSO NACIONAL DE MILHO E SORGO-Águas de Lindóia-26 a. 2012. 
Kappes, C.; Andrade, J. A. C.; Arf, O.; Oliveira, A. C.; Arf, M. V.; Ferreira, J. P. Desempenho de híbridos de milho em diferentes arranjos espaciais de plantas. Bragantia, 2011, 70, 2, 334-343.

Kappes, C.; Arf, O.; Arf, M. V.; Ferreira, J. P.; Dal Bem, E. A.; Portugal, J. R.; Vilela, R. G. Inoculação de sementes com bactérias diazotróficas e aplicação de nitrogênio em cobertura e foliar em milho. Semina: Ciências Agrárias, 2013, 34, 2, 527-528.

Kavadia, A.; Vayenas, D. V.; Pavlou, S.; Aggelis, $G$. Dynamics of free-living nitrogen-fixing bacterial populations and nitrogen fixation in a two-prey-onepredator system. Ecological Modelling, 2008, 218, 323338.

Lemos, J. M. Resposta de cultivares de trigo à inoculação em sementes com Azospirillum brasilense, e à adubação nitrogenada em cobertura. Dissertação (Mestrado em Agronomia) Universidade estadual do Oeste do Paraná, PR, 2011, 1-63.

Nakao, A. H.; Souza, M. F. P.; Dickmann, L.; Centeno, D. C.; Rodrigues, R. A. F. Resposta do sorgo granífero à aplicação de diferentes doses e épocas de inoculante (Azospirillum brasiliense) via foliar. Enciclopédia Bioesfera, 2014, 10, 18, 2702-2714.

Ohland, R. A. A.; Souza, L. C. F.; Hernani, L. C.; Marchetti, M. E.; Gonçalves, M. C. Culturas de cobertura do solo e adubação nitrogenada no milho em plantio direto. Ciência e Agrotecnologia, 2005, 29, 3, 538-544.

Okon, Y.; Vanderleyden, J. Root-associated Azospirillum species can stimulate plants. Applied and Environment Microbiology, 1997, 6, 7, 366-370.

Portugal, J. R.; Arf, O.; Longui, W. V.; Gitti, D. C.; Barbieri, M. K. F.; Gonzaga, A. R.; Teixeira, D. S. Inoculação com Azospirillum brasilense via foliar associada a doses de nitrogênio em cobertura na cultura do milho. In: Anais do $29^{\circ}$ Congresso Nacional de Milho e Sorgo. Campinas: Instituto Agronômico, 2012, 1413-1420.

Quadros, P. D.; Roesch, L. F. W.; Silva, P. R. F.; Vieira, V. M.; Roehrs, D. D.; Camargo, F. A. O. Desempenho agronômico a campo de híbridos de milho inoculados com Azospirillum. Ceres, 2015, 61, 2, 209-218.
Rampim, L.; Costa, A. C. R; Nacke, H.; Klein, J.; Guimarães, V. F. Qualidade fisiológica de sementes de três cultivares de trigo submetidas à inoculação e diferentes tratamentos. Journal of Seed Science, 2012, $34,4,678-685$.

Rocha, A. F. S.; Costa, R. R. G. F. Desempenho de Urochloa brizantha CV Paiaguás inoculada com Azospirillum brasilense e diferentes doses nitrogênio. Global Science and Technology, 2018, 11, 3, 177-186.

Sala, V. M. R.; Cardoso, E. J. B. N.; Freitas, J. G.; Silveira, A. P. D. Resposta de genótipos de trigo à inoculação de bactérias diazotróficas em condições de campo. Pesquisa Agropecuária Brasileira, 2007, 42, 6, 833-842.

Santos, H.G. dos, et al. Sistema brasileiro de classificação de solos. 2.ed. Rio de Janeiro: Embrapa Solos, 2006. 306p

Silva, F.A.S.; Azevedo, C.A.V. Principal Components Analysis in the Software Assistat-Statistical Attendance. In: World congress on computers in agriculture, 7 , Reno-NV-USA: American Society of Agricultural and Biological Engineers, 2009.

Sousa, D. M. G.; Lobato, E. Cerrado: correção do solo e adubação. Planaltina: Embrapa Cerrados, 2004, 1-416.

Taiz, L.; Zeiger, E.; Møller, I. M.; Murphy, A. Fisiologia e desenvolvimento vegetal. Artmed Editora, 2017, 888p.

Vanderlip, R.L. How a sorghum plant develops. Kansas State University Agricultural. Experiment Station and Cooperative Extension Service. 1999, 1-20.

Vazquez, G. H.; Silva, M. R. R. Da.; Sousa, J. F. Dos S.; Morais, B. F. De. Fontes de Azospirillum brasilense e Doses de Nitrogênio em Cobertura na Cultura do Sorgo Granifero. Congresso Nacional De Milho e Sorgo, 29. Anais... Água de Lindóia, 2012, 1627-1633.

Verona, D. A.; Duarte Júnior, J. B.; Rossol, C. D.; Zoz, T.; Costa, A. C. T. Tratamento de sementes de milho com Zeavit $₫$, Stimulate $₫$ e inoculação com Azospirillum sp. In: $28^{\circ}$ Congresso Nacional de Milho e Sorgo, Goiânia. Anais, Associação Brasileira de Milho e Sorgo. CDROM. 2010, 3731-3737. 